\title{
Radical Polymerization Rate of Methyl Methacrylate above $10 \%$ Conversion under the Condition of Predominant Transfer
}

\author{
Katsukiyo ITO \\ Government Industrial Research Institute, Nagoya, \\ Kita-ku, Nagoya 462, Japan
}

(Received April 5, 1984)

\begin{abstract}
In the radical polymerization of methyl methacrylate at $20^{\circ} \mathrm{C}$ where transfer predominates, termination rates were estimated over a wide range of conversion and discussed on the basis of the entanglement and reptation theories. The critical chain length can be expressed by $n_{\mathrm{c}} \propto c^{-2}$ ( $c$, volume fraction of polymer), where the rate of termination between radicals with chain length shorter than $n_{\mathrm{c}}$ is independent of chain length. This equation was confirmed using data already reported. The final conversion is discussed experimentally and theoretically.

KEY WORDS Methyl Methacrylate / High Conversion / Kinetics / Termination Rate / Entanglement / Transfer / Final Conversion /
\end{abstract}

Since the autoacceleration of polymerization rate was discovered by Tromsdorff, ${ }^{1}$ many workers have attempted theoretical explanations for it. Because the rate is accelerated more at higher rates of initiation, many studies have been focused on polymerization at such rates. However, at a high rate, the molecular weight distribution of polymers is very complex. ${ }^{2,3}$ This complexity should be correlated to the fact that termination rate depends on chain length. ${ }^{4,5}$ To estimate this dependency, there are two theories, the entanglement ${ }^{6}$ and reptation theories, ${ }^{7}$ the latter being based on the assumption that a polymer shows snake-like movement. Cardenas and O'Driscoll ${ }^{8}$ used the entanglement theory, but did not consider the dependency of the termination rate on chain length. Ito ${ }^{9}$ used the reptation theory, and stated the possibility of the dependence of the propagation rate constant on conversion above $50 \%$. Recently, Ebihara et al. ${ }^{10}$ revealed that the specific rate of propagation does not depend on conversion below $80 \%$. Other treatments ${ }^{11-13}$ have one or both of these weak points, so that autoac- celeration still cannot be correlated to the basic physical theories.

In the present paper, the author has attempted to gain a basic understanding of autoacceleration. Methyl methacrylate (MMA) was polymerized when transfer predominated. The respective molecular weight is quite simple, and the data obtained should be easy to examine on basic physical grounds.

\section{Theory}

Some rate equations used previously ${ }^{5,9,14,15}$ for termination between polymer radicals with $\mathrm{n}$ and $\mathrm{s}$ may be generallized as

$$
\begin{aligned}
& k_{\mathrm{t}, \mathrm{ns}}=k\left(\zeta_{\mathrm{n}}+\zeta_{\mathrm{s}}\right) \\
& \zeta_{\mathrm{n}}=n^{-\mathrm{a}} \text { at } n<n_{\mathrm{c}} \\
& \zeta_{\mathrm{n}}=n_{\mathrm{c}}{ }^{b-a} n^{-b} \text { at } n \geq n_{\mathrm{c}} \\
& n_{\mathrm{c}}=n_{\mathrm{co}} c^{-\gamma}
\end{aligned}
$$

An average termination rate is written as ${ }^{9,14}$

$$
\overline{k_{\mathrm{t}}}=2 k \bar{k}
$$




$$
\begin{gathered}
\bar{k}=\sum_{n=1}^{n_{\mathrm{c}}} n^{-a}\left(\left[\mathrm{~N}_{n}\right] /[\mathrm{N}]\right) \\
\quad+n_{\mathrm{c}}^{b-a} \sum_{n_{\mathrm{c}}}^{\infty} n^{-b}\left(\left[\mathrm{~N}_{n}\right] /[\mathrm{N}]\right) \\
\simeq \int_{0}^{n_{\mathrm{c}}} n^{-a}\left(\left[\mathrm{~N}_{n}\right] /[\mathrm{N})\right] \mathrm{d} n \\
\quad+n_{\mathrm{c}}{ }^{b-a} \int_{n_{\mathrm{c}}}^{\infty} n^{-b}\left(\left[\mathrm{~N}_{n}\right] /[\mathrm{N}]\right) \mathrm{d} n
\end{gathered}
$$

The chain length distribution of polymer radicals is expressed by eq 8 when transfer predominates.

$$
\left[\mathrm{N}_{n}\right] /[\mathrm{N}] \simeq C_{\mathrm{tr}} \exp \left(-C_{\mathrm{tr}} n\right)
$$

When $a=0,{ }^{5,15}$ as shown in Appendix, an average $\bar{k}$ is given by

$$
\bar{k} \simeq[1+1 /(b-1)] C_{\mathrm{tr}} n_{\mathrm{c}}
$$

When $a=1 / 2,{ }^{9,14}$ one also obtains (see Appendix),

$$
\bar{k} \simeq[2+1 /(b-1)] C_{\mathrm{tr}} n_{\mathrm{c}}{ }^{1 / 2}
$$

$\gamma$ was reported to be $1,{ }^{16} 1.25,{ }^{17}$ or $2 .{ }^{18}$ To find the best value for $\gamma$, eq 11 may be used in view of eq 5,9 , and 10 .

$$
\overline{k_{\mathrm{t}}} \propto k c^{-\delta}
$$

If $k$ is evaluated using the free volume theory, ${ }^{4,5,9,12,19}$ the following linear relationship between $\left(\bar{k}_{\mathrm{t}} c^{\delta}\right)$ and $v_{\mathrm{f}}{ }^{-1}$ is obtained: ${ }^{9}$

$$
\ln \left(\overline{k_{\mathrm{t}}} c^{\delta}\right)=\text { const }-\gamma^{*} v^{*} / v_{\mathrm{f}}
$$

where $^{20}$

$$
\begin{aligned}
v_{\mathrm{f}}= & \left\{\left[25+0.48\left(T-T_{\mathrm{gp}}\right)\right](1-c)\right. \\
& \left.+\left[25+T-T_{\mathrm{gm}}\right] c\right\} / 1000
\end{aligned}
$$

\section{EXPERIMENTAL}

Commercial MMA was washed three times with $5 \%$ sodium hydroxide solution and twice with water. It was dried over anhydrous magnesium sulfate and distilled. After prepolymerization in the absence of initiator, it was again distilled fractionally under reduced pressure $\quad\left(b p=45.5-46.0^{\circ} \mathrm{C} / 100 \quad \mathrm{mmHg}\right)$. Commercial 2,2'-azobisisobutyronitrile (AIBN) was recrystallized three times from ethanol. Pure diisopropyl dicarbonate (DIPDC) was supplied by Nippon Oils and Fats Co., Ltd.

The initiator and monomer in an ampoule (diameter $=4 \mathrm{~mm}$ ) were degassed by a successive freezing and melting procedure, and the ampoule was sealed under a vacuum of about $10^{-3} \mathrm{mmHg}$. The bulk polymerization was carried out by maintaining the ampoule at $20.0 \pm 0.02{ }^{\circ} \mathrm{C}$ for a given time. The contents in the ampoule were diluted with tetrahydrofuran containning $0.006 \%$ of hydroquinone. Methanol was poured into the solution very slowly to precipitate the polymers gradually. This process for purification of the polymers was repeated twice. The polymers purified were isolated, dried, and weighed. The weight average molecular weight was measured by the light scattering method, using a Toyosoda LS 8 and HLC-802A and tetrahydrofuran as the solvent.

\section{RESULTS AND DISCUSSION}

\section{Polymerization below $70 \%$ Conversions}

Time-conversion curves are shown in Figure 1. The curve obtained at $[\mathrm{AIBN}]=$ $0.308 \mathrm{~mol} \mathrm{dm}^{-3}$ is very close to that at $[D I P D C]=0.0069$ before the final stage. There is no difference between the curves obtained at $[\mathrm{AIBN}]=0.0256$ and $[\mathrm{DIPDC}]=0.00086$ below $70 \%$ conversion $(x<0.7)$. This indicates that the difference in the decomposition processes of AIBN ${ }^{21,22}$ and DIPDC, ${ }^{22,23}$ as shown in eq 14 and 15 , scarcely reflects the timeconversion curves prior to the final stage.

$$
\begin{aligned}
& \mathrm{AIBN} \rightarrow 2\left(\mathrm{CH}_{3}\right)_{2} \mathrm{CCN}+\mathrm{N}_{2} \\
& \text { DIPDC } \rightarrow 2\left(\mathrm{CH}_{3}\right)_{2} \mathrm{CHOCOO} . \\
& \stackrel{\beta \text {-scission }}{\longrightarrow} 2\left(\mathrm{CH}_{3}\right)_{2} \mathrm{CHO} \cdot+2 \mathrm{CO}_{2}
\end{aligned}
$$

To estimate $C_{\mathrm{tr}}$ for the monomer and $k_{\mathrm{t}} / k_{\mathrm{p}}{ }^{2}$ at 


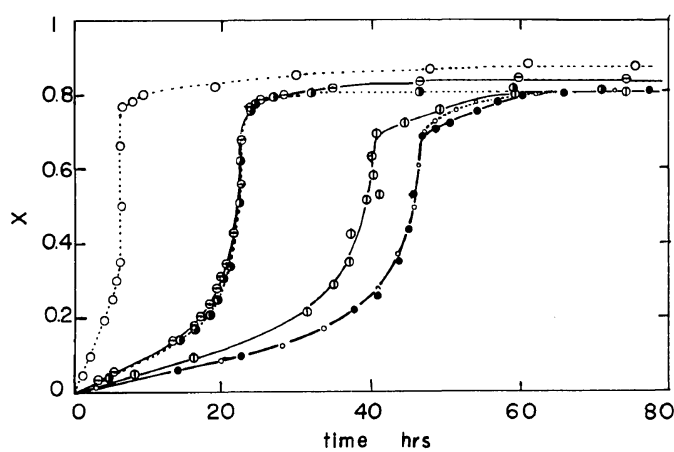

Figure 1. Time-conversion curves when [DIPDC] $=$ $0.207 \mathrm{~mol} \mathrm{dm}^{-3}$ (O), 0.0069 (O), 0.00086 (o) and $[\mathrm{AIBN}]=0.308(\Theta), 0.0385(\mathbb{1}), 0.0256(\bullet)$.

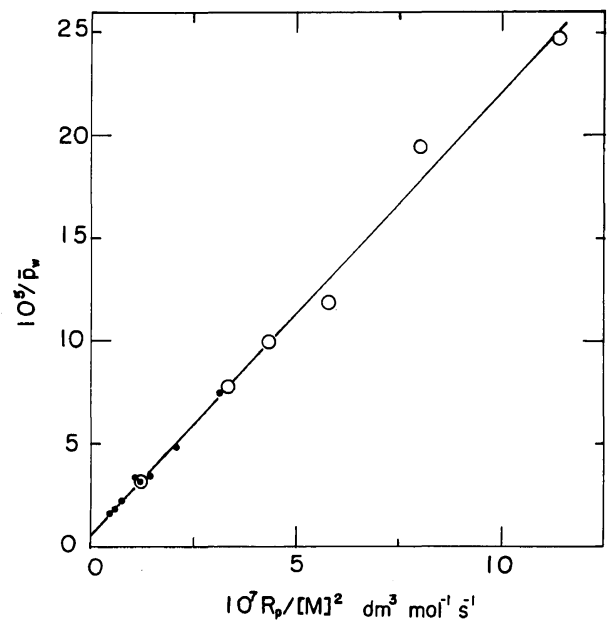

Figure 2. Relationship between $\bar{p}_{w}$ and $R_{\mathrm{p}}$ in the presence of DIPDC (O) and AIBN (O) when $x<0.05$.

the initial stage $(x<0.05)$, a conventional relationship between $1 / \bar{p}_{\mathrm{w}}$ and $R_{\mathrm{p}} /[\mathrm{M}]^{2}$ was obtained, as shown in Figure 2. The $C_{\mathrm{tr}}$ value was found to be $1.0 \times 10^{-5}$ from the intercept, which is nearly equal to $1.28 \times 10^{-5}$ at $0^{\circ} \mathrm{C}$ and $1.17 \times 10^{-5}$ at $30^{\circ} \mathrm{C}^{24}$ The $\bar{k}_{\mathrm{t}} / k_{\mathrm{p}}{ }^{2}$ value was found to be $432 \mathrm{~mol} \mathrm{~s} / \mathrm{dm}^{-3}$ which is in good agreement with 529 at $20^{\circ} \mathrm{C}^{25}$ and 300 322 at $22.5^{\circ} \mathrm{C}$ at $R_{\mathrm{i}}=8.36 \times 10^{-9}-2.83 \times 10^{-8}$ $\mathrm{mol} \mathrm{dm}{ }^{-3} \mathrm{~s}^{-1}{ }^{33}$ The initiator efficiencies were calculated to be $f_{\mathrm{AIBN}}=0.50$ and $f_{\mathrm{DIPDC}}=0.93$, using $\quad \overline{k_{\mathrm{t}}} / k_{\mathrm{p}}{ }^{2}=432, \quad R_{\mathrm{p}}=6.0 \times 10^{-5}[\mathrm{AIBN}]^{1 / 2}$ and $2.8 \times 10^{-4}$ [DIPDC] $]^{1 / 2} \mathrm{~mol} \mathrm{dm}^{-3} \mathrm{~s}^{-1}$ at $x<0.05$, and $k_{\mathrm{d}}=1.78 \times 10^{-8} \mathrm{~s}^{-1}(\mathrm{AIBN})^{26}$

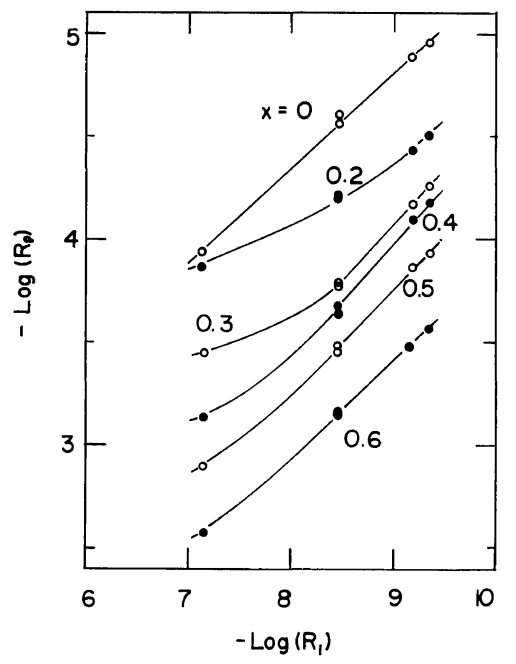

Figure 3. Relationship between $R_{\mathrm{p}}$ and $R_{\mathrm{i}}$ at each conversion.

and $1.86 \times 10^{-7} \mathrm{~s}^{-1}$ (DIPDC). ${ }^{23}$ In some papers, ${ }^{9,27,28}$ it was stated that the initiator efficiency hardly depends on conversion prior to the final stage. This independence is consistent with the fact that the time-conversion curve is independent of the differences between reactions (14) and (15) below 70\% conversion.

When the termination rate depends on chain length and polymers are produced by termination, the relationship between $R_{\mathrm{p}}$ and [C] deviates from the conventional equation, $R_{\mathrm{p}} \propto[\mathrm{C}]^{1 / 2}{ }^{4,29}$ This is evident in Figure 3 when $R_{\mathrm{i}}>3 \times 10^{-9} \mathrm{~mol} \mathrm{dm}^{-3} \mathrm{~s}^{-1}$ and has also been reported before when $R_{\mathrm{i}}=8.36 \times 10^{-9}$ $2.83 \times 10^{-8} .{ }^{33}$ However, when polymers are produced by transfer, there is no deviation from the conventional equation, even if the termination rate depends on chain length. ${ }^{4,29}$ This is also the case when $R_{\mathrm{i}}<3 \times 10^{-9}$ (Figure 3 ). These findings were confirmed by the data on the molecular weight. The instantaneous weight average degree of polymerization can be estimated from ${ }^{3,9}$

$$
\bar{p}_{w}=\mathrm{d}\left(x \bar{P}_{w}\right) / \mathrm{d} x
$$

The relationship between $x \bar{P}_{w}$ and $x$ is shown in Figure 4. When [DIPDC] $=0.207 \mathrm{~mol} \mathrm{dm}^{-3}$, 
K. ITo

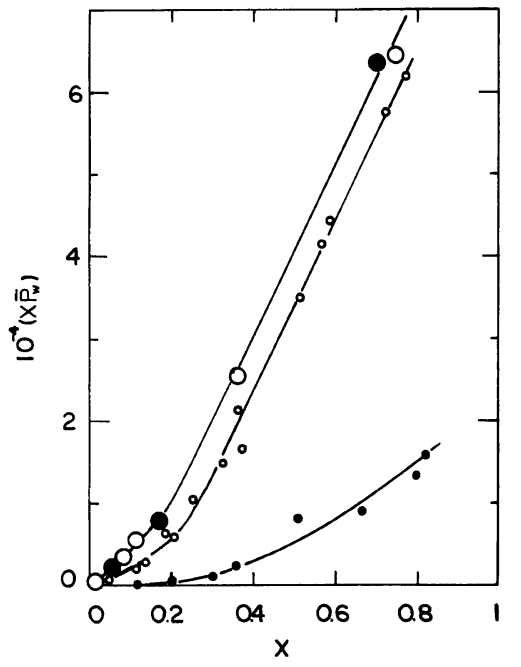

Figure 4. Estimation of $\bar{p}_{w}$ at each conversion when $[\mathrm{DIPDC}]=0.207 \mathrm{~mol} \mathrm{dm}^{-3}(\bullet), 0.0069$ (०), 0.00086( and $[\mathrm{AIBN}]=0.0256(\mathrm{O})$.

Table I. Kinetic data of the polymerization when $[A I B N]=0.0127 \mathrm{~mol} \mathrm{dm}^{-3}$ and $[$ DIPDC $]=0.00086 \mathrm{~mol} \mathrm{dm}^{-3}$

\begin{tabular}{|c|c|c|c|c|}
\hline \multirow{2}{*}{$x$} & {$[\mathrm{M}]$} & \multirow{2}{*}{$c$} & \multirow{2}{*}{$\frac{10^{5} R_{\mathrm{p}}}{\mathrm{mold \textrm {m } ^ { - 3 } \mathrm { s } ^ { - 1 }}}$} & \multirow{2}{*}{$\frac{10^{-4} k_{\mathrm{t}}^{*}}{\mathrm{dm}^{3} \mathrm{~mol}^{-1} \mathrm{~s}^{-1}}$} \\
\hline & $\mathrm{mol} \mathrm{dm}^{-3}$ & & & \\
\hline 0 & 9.40 & 0 & 1.09 & 3320 \\
\hline 0.1 & 8.42 & 0.082 & 1.30 & 2010 \\
\hline 0.15 & 8.30 & 0.123 & 2.04 & 743 \\
\hline 0.2 & 7.90 & 0.166 & 3.06 & 298 \\
\hline 0.25 & 7.49 & 0.210 & 3.93 & 161 \\
\hline 0.3 & 7.07 & 0.255 & 4.99 & 90.2 \\
\hline 0.35 & 6.64 & 0.302 & 6.16 & 52.3 \\
\hline 0.4 & 6.20 & 0.346 & 7.21 & 33.2 \\
\hline 0.45 & 5.75 & 0.394 & 9.59 & 16.0 \\
\hline 0.5 & 5.28 & 0.443 & 11.7 & 7.42 \\
\hline 0.55 & 4.81 & 0.493 & 18.3 & 3.11 \\
\hline 0.6 & 4.33 & 0.544 & 27.6 & 1.11 \\
\hline
\end{tabular}

* Calculated by setting up $k_{\mathrm{p}}=277 .^{25}$

$\bar{p}_{w}$ is 4030 at $x<0.05$ and increases with increasing conversion, the polymerization rate deviating from $R_{\mathrm{p}} \propto[\mathrm{C}]^{1 / 2}$. When [DIPDC] $=$ $0.0069, \bar{p}_{w}$ increases from $13200(x<0.05)$ to 108000 at $x \simeq 0.3$, the rate slightly deviating from $R_{\mathrm{p}} \simeq[\mathrm{C}]^{1 / 2}$ (Figure 3). When [DIPDC] $=$ 0.00086 and $[\mathrm{AIBN}]=0.0256, \bar{p}_{w}$ starts from

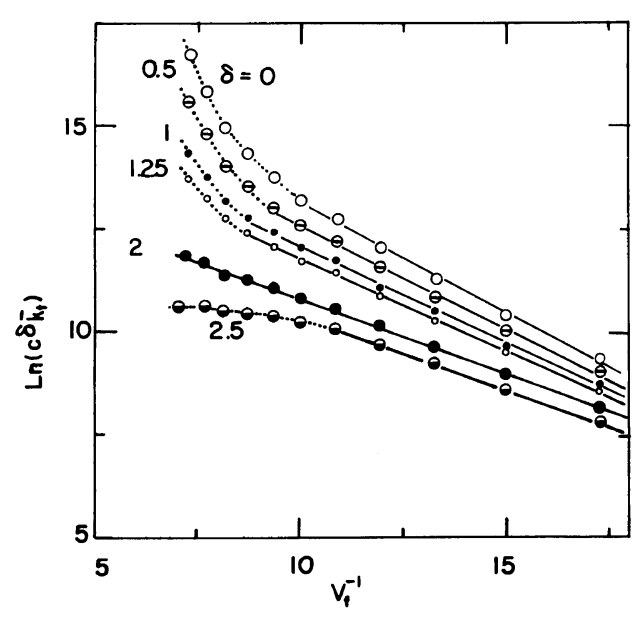

Figure 5. Examination of the linearity of the relationship between $\ln \left(c^{\delta} \bar{k}_{\mathfrak{t}}\right)$ and $v_{\mathrm{f}}^{-1}$.

32000 , reaches 108000 at $x \simeq 0.15$, and remains at 108000 . No deviation was observed in this case. It is concluded that eq 12 is applicable to the kinetic data obtained when [DIPDC]= 0.00086 and $[\mathrm{AIBN}]=0.0256$. Free volume is calculated by setting $T_{\mathrm{gp}}=114^{\circ} \mathrm{C}$ and $T_{\mathrm{gm}}=$ $-106^{\circ} \mathrm{C}^{20}$ Equation 12 was applied to the data shown in Table I (Figure 5). From the linearity over a wide range of conversion, $\delta=$ 1.25 and 2 fit the data, and $\delta=2$ is somewhat better. If $a=0, \delta$ is equal to $\gamma$. Thus $\gamma=2$. This corresponds to the previous result, ${ }^{27}$ obtained from the effect of the surrounding polymers of a polymer radical on the termination rate. Thus, $n_{\mathrm{c}} \propto c^{-2}$ is used hereinafter, where $\gamma^{*} v^{*}=0.37$ is estimated from the slope. Here, if $a=1 / 2, \gamma=2$ cannot be obtained from $\delta=2$, as evident from eq 4 and 10. Accordingly, $a=0$ should be better with $\gamma$ as 2 . This means that the termination rate between polymers with $n<n_{\mathrm{c}}$ hardly depends on the chain length. The diffusion-controlled rate is given by ${ }^{9,30,31}$

$$
k_{\mathrm{t}, n s}=4 \pi D R
$$

This shows that equations such as $D \propto n^{-1 / 2}$ (Stokes' law) and $R \propto n^{1 / 2}$ (random flight) ${ }^{32}$ may be applicable; i.e., the rate becomes independent of chain length. The data ${ }^{33}$ are examined by setting $n_{\mathrm{co}}=300 .^{6,27}$ The values of $2 k$ 
Table II. Analysis of kinetic data at $22.5^{\circ} \mathrm{C}^{33}$

\begin{tabular}{|c|c|c|c|c|}
\hline \multirow{2}{*}{$x$} & \multirow{2}{*}{$10^{5} R_{\mathrm{i}} / R_{\mathrm{p}}$} & \multirow{2}{*}{$\bar{n}_{\mathrm{c}}$} & \multirow{2}{*}{$\bar{k}$} & \multirow{2}{*}{$\frac{2 k / 10^{4}}{\mathrm{dm}^{3} \mathrm{~mol}^{-1} \mathrm{~s}^{-1}}$} \\
\hline & & & & \\
\hline \multirow[t]{2}{*}{$0.1^{\mathrm{a}}$} & 19.7 & 45731 & $1^{*}$ & $2730^{*}$ \\
\hline & & & $1 * *$ & $2730 * *$ \\
\hline \multirow[t]{2}{*}{0.2} & 8.67 & 11019 & $0.889^{*}$ & $817^{*}$ \\
\hline & & & $0.898^{* *}$ & $808 * *$ \\
\hline \multirow[t]{2}{*}{0.3} & 3.30 & 4650 & $0.315^{*}$ & $451^{*}$ \\
\hline & & & $0.331^{* *}$ & $429 * *$ \\
\hline \multirow[t]{2}{*}{0.4} & 2.11 & 2506 & $0.1327^{*}$ & $673^{*}$ \\
\hline & & & $0.1412 * *$ & $633^{* *}$ \\
\hline \multirow[t]{2}{*}{0.5} & 1.964 & 1536 & $0.0805^{*}$ & $501^{*}$ \\
\hline & & & $0.0860^{* *}$ & $469^{* *}$ \\
\hline \multirow[t]{2}{*}{0.6} & 2.64 & 1017 & $0.0617 *$ & $80.7^{*}$ \\
\hline & & & $0.0660 * *$ & $75.4^{* *}$ \\
\hline \multirow[t]{2}{*}{0.7} & 3.53 & 712 & $0.0596^{*}$ & $9.47^{*}$ \\
\hline & & & $0.0638^{* *}$ & $8.84^{* *}$ \\
\hline $0.1^{b}$ & 12.6 & 45731 & $1^{*}$ & $3600^{*}$ \\
\hline 0.2 & 4.75 & 11019 & $0.738^{*}$ & $677 *$ \\
\hline 0.3 & 1.667 & 4650 & $0.207^{*}$ & $426^{*}$ \\
\hline $0.1^{\mathrm{c}}$ & 10.5 & 45731 & $1^{*}$ & $2640 *$ \\
\hline 0.2 & 3.52 & 11019 & $0.632 *$ & $664^{*}$ \\
\hline 0.3 & 1.26 & 4650 & $0.1757^{*}$ & $356^{*}$ \\
\hline 0.4 & 0.849 & 2506 & $0.0805^{*}$ & $604 *$ \\
\hline 0.5 & 0.900 & 1536 & $0.0508^{*}$ & $313^{*}$ \\
\hline 0.6 & 1.21 & 1017 & $0.0182 *$ & $149 *$ \\
\hline 0.7 & 2.24 & 712 & $0.0442 *$ & $17.8^{*}$ \\
\hline
\end{tabular}

a $R_{\mathrm{i}}=2.83 \times 10^{-8} \mathrm{~mol} \mathrm{dm}^{-3} \mathrm{~s}^{-1}$.

b $1.20 \times 10^{-8}$.

c $8.36 \times 10^{-9}$.

* $b=3.4, * * b=2.9$.

and $\bar{k}$ are calculated by a modification of the previous method ${ }^{9}$ for $a \simeq 0$ and $b=2.9$ or 3.4 and the results are shown in Table II. A line with a slope of $\gamma^{*} v^{*}=0.37$ is shown in Figure 6. This line is apparently consistent with the data in Table II. However, the difference between $b=2.9$ and 3.4 is not pronounced, so that $D R \simeq$ const when $n<n_{\text {c }}$ cannot be determined from the data in Table II. Boots stated that the change in $b$ slightly reflects the calculated values when $(b-a)>1 .^{14}$ This is also important to the present discussion.

\section{Final Conversion}

The final conversion and molecular weight

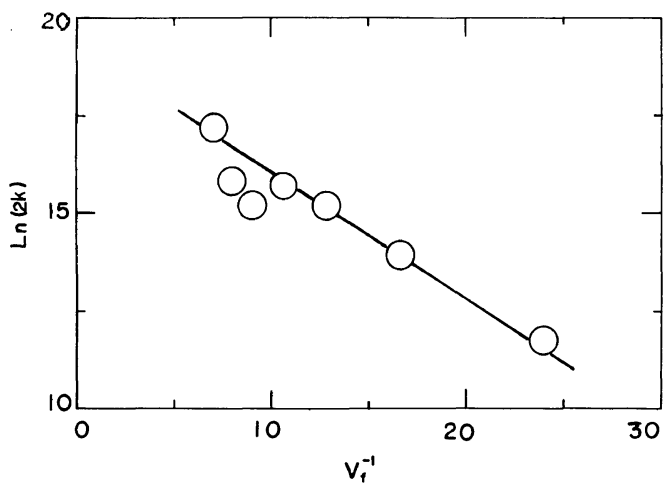

Figure 6. Relationship between $2 k$ and $v_{\mathrm{f}}$ in the polymerization $22.5^{\circ} \mathrm{C}^{33}$

Table III. Final conversions

\begin{tabular}{lccccc}
\hline & {$[\mathrm{C}]$} & \multicolumn{2}{c}{ Time } & & \\
\cline { 5 - 6 } Initiator & $\frac{\mathrm{h}}{\mathrm{n}}$ & & & & $10^{-6} M_{w}$ \\
& $\mathrm{n}$ & & & \\
\hline AIBN & 5.06 & & $47-190$ & $0.83 \pm 0.01$ & $6.4 \pm 0.3$ \\
AIBN & 2.53 & & $95-190$ & $0.82 \pm 0.01$ & \\
AIBN & 1.26 & $95-167$ & $0.80 \pm 0.01$ & \\
AIBN & 0.63 & $95-190$ & $0.80 \pm 0.01$ & $7.3 \pm 0.5$ \\
AIBN & 0.42 & $95-166$ & $0.80 \pm 0.005$ & $9.0 \pm 0.5$ \\
DIPDC & 5.74 & $30-96$ & $0.87 \pm 0.03$ & $5.3 \pm 0.2$ \\
DIPDC & 0.191 & $48-240$ & $0.80 \pm 0.01$ & $8.9 \pm 0.5$ \\
DIPDC & 0.024 & $96-240$ & $0.80 \pm 0.01$ & $8.6 \pm 0.5$ \\
\hline
\end{tabular}

are shown in Table III. When $[\mathrm{C}]>1 \%$, the final conversion increased with an increase in [C]. This resembles the increase in the final conversion with increasing solvent fraction. ${ }^{34}$ Perhaps, the initiators mainly serve as solvents. When $[\mathrm{C}]<1 \%$, the final conversion was $0.80 \pm 0.01$. This is in good agreement with $x=$ 0.786 calculated from ${ }^{20}$

$$
\phi_{\mathrm{p}, \mathrm{gt}}=\frac{T-T_{\mathrm{gm}}}{T-T_{\mathrm{gm}}+0.48\left(T-T_{\mathrm{gp}}\right)}
$$

Ebihara et al. ${ }^{10}$ discussed the magnitude of the propagation rate constant using ${ }^{35,36}$

$$
k_{\mathrm{p}}=k_{\mathrm{c}} k_{1} /\left(k_{-1}+k_{\mathrm{c}}\right)
$$

On evaluating $k_{1}$ as a diffusion-controlled quenching rate constant, it was found to be $1.6 \times 10^{9} \mathrm{dm}^{3} \mathrm{~mol}^{-1} \mathrm{~s}^{-1}$ at $x=0$, decrease slowly with polymerization, and reach 
$6.6 \times 10^{7}$ at $x=0.89$ at $20^{\circ} \mathrm{C}$. These values are so large that the propagation cannot shift to a diffusion-controlled reaction, because $k_{\mathrm{p}}$ $\left(=k_{\mathrm{c}} k_{1} / k_{-1}\right)=130-750 \mathrm{dm}^{3} \mathrm{~mol}^{-1} \mathrm{~s}^{-1}$ at $20{ }^{\circ} \mathrm{C}^{48}$ Further, the relationship between the quenching rate constant and conversion does not follow the free volume theory expressed by eq 13. That is, in view of eq 19 , when $k_{-1} /$ $k_{\mathrm{c}} \gg 10^{7}$, the propagation rate may become diffusion-controlled. But, in the light of the data by Ebihara et al., $k_{-1} / k_{1} \gg 10^{7}$ is impossible since $k_{\mathrm{p}}=130-750$. Essentially, the concept of "a translational diffusioncontrolled reaction" must be defined for a reaction when a few or more inert molecules exist between two reactants. That is, if a reactant is situated besides other, no translational displacement is necessary to occur a reaction between them. In radical polymerization, about ten small molecules (solvents, monomers, and monomer units) surround a radical position on the polymer chain. Thus, when $x<0.9$, there should exist a few or more monomers in the vicinity of the radical position. Consequently, the concept of "the translational diffusion-controlled reaction" is unnecessary for understanding the actual propagation rate when $x<0.9$. It is concluded that $k_{\mathrm{p}}$ is independent of conversion below that of $89 \%$ and the final conversions in Table III do not occur when $k_{\mathrm{p}} \rightarrow 0$. Essentially, the final conversion is defined as that when

$$
-\mathrm{d}[\mathrm{M}] / \mathrm{d} t \equiv R_{\mathrm{p}} \rightarrow 0 \text {. }
$$

Here, in

$$
R_{\mathrm{p}}\left\{=\left(2 f k_{\mathrm{d}} / \bar{k}_{\mathrm{t}}\right)^{1 / 2} k_{\mathrm{p}}[\mathrm{C}]^{1 / 2}[\mathrm{M}]\right\} \rightarrow 0,
$$

[C], [M], $k_{\mathrm{p}}$, and $k_{\mathrm{d}}$ are not zero and $\bar{k}_{\mathrm{t}}$ decreases with increasing $x$. Thus, inevitably, the final conversion becomes equal to that when $f \rightarrow 0$. The final conversions in Table III must be explained from the difference between eq 14 and 15 . When a two bond initiator such as AIBN is used, its efficiency is given as $f=D_{\mathrm{S}} /\left(A+D_{\mathrm{S}}\right){ }^{38,40-43}$ Equations in terms of efficiency for one bond initiators ${ }^{39,44}$ such as DIPDC are more complex, ${ }^{38,45-47}$ since there are two step reactions in A-cage and B-cage and $\beta$-scission between them. Pryor and $\mathrm{Smith}^{39}$ stated that a rate constant for $\beta$-scission in the decomposition of a hypothetical initiator as a peroxy compound is estimated to be $k_{\beta}=3 \times 10^{10} \mathrm{~s}^{-1}$. This value corresponds to $k_{\beta}^{\prime} \simeq 10^{11} \mathrm{~s}^{-1}$ by Ito's theory. ${ }^{38}$ When $k_{\beta}^{\prime} \gg 10^{15} D_{\mathrm{S}}\left(\simeq 10^{10}\right.$ at $\left.x \rightarrow 0\right)$, the initiator efficiency for a two bond initiator becomes equal to that for a one bond initiator. ${ }^{39}$ If the value $k_{\beta}^{\prime} \simeq 10^{11}$ is acceptable at low conversions in the decomposition of DIPDC, the inequality $k_{\beta}^{\prime} \gg 10^{15} D_{\mathrm{S}}$ becomes complete at high conversions because of the decrease in $D_{\mathrm{s}}$. Therefore, the equation $f \simeq D_{\mathrm{S}} /\left(A+D_{\mathrm{S}}\right)$ may be also used in the polymerization initiated by DIPDC. From the experiments, $f_{\text {AIBN }}=0.50$ and $f_{\text {DIPDC }}=0.93$ at low conversions, and therefore $A$ is comparable to $D_{\mathrm{S}}$. This means that a large decrease in $D_{\mathrm{S}}$ by $10^{-7}$ is unnecessary, in order to consider the decrease in $f$ at high conversions. From the timeconversion curves when $x>0.7$ (Figure 1), it is estimated that the polymerization rate at $[D I P D C]=0.00086 \mathrm{~mol} \mathrm{dm}^{-3}$ is higher than that at $[\mathrm{AIBN}]=0.0256$. This should be understood by $f_{\text {DIPDC }}>f_{\text {AIBN }}$ in equation $R_{\mathrm{p}} \propto f^{1 / 2}$ where $A_{\mathrm{DIPDC}} / A_{\mathrm{AIBN}} \simeq 0.06$. It was formerly stated, as the main reason for the higher final conversion at higher [C], that the initiators serve as solvents. However, this reason may be insufficient to explain the result that, in spite of $[\mathrm{DIPDC}] \simeq[\mathrm{AIBN}]$, the final conversion in the polymerization initiated by DIPDC was higher than that by AIBN. Perhaps, this result can be explained by the possibility that the conversion at $f_{\mathrm{DIPDC}} \rightarrow 0$ is higher than that at $f_{\text {AIBN }} \rightarrow 0$. The final conversion calculated by eq 18 should be real, regardless of the above discussion, since the size of a primary radical hardly differs from that of the monomer and the diffusing behavior of the former resembles that of the latter, according to the Stokes' law. In a glassy state of polymers, there are various reactions ${ }^{49}$ whose rates may be com- 
parable to the propagation rate related to the propagation displacements in the final stage of polymerization. ${ }^{9,37}$ Thus, to discuss the final conversion in more detail, such reaction rates must be analyzed.

\section{APPENDIX}

The first term of eq 7 is calculated as,

$$
\begin{gathered}
\int_{0}^{n_{\mathrm{c}}} C_{\mathrm{tr}} \exp \left(-C_{\mathrm{tr}} n\right) \mathrm{d} n=1-\exp \left(-C_{\mathrm{tr}} n\right) \\
\simeq C_{\mathrm{tr}} n_{\mathrm{c}} \quad \text { when } \quad C_{\mathrm{tr}} n_{\mathrm{c}} \ll 1 \\
\int_{0}^{n_{\mathrm{c}}} C_{\mathrm{tr}} n^{-1 / 2} \exp \left(-C_{\mathrm{tr}} n\right) \mathrm{d} n \\
=2 C_{\mathrm{tr}}^{1 / 2} \int_{0}^{u_{\mathrm{c}}} \exp \left(-u^{2}\right) \mathrm{d} u \\
=2 C_{\mathrm{tr}} n_{\mathrm{c}}{ }^{1 / 2}\left(1-C_{\mathrm{tr}} n_{\mathrm{c}} / 3+\cdots\right) \\
\simeq 2 C_{\mathrm{tr}} n_{\mathrm{c}}{ }^{1 / 2} \quad \text { when } \quad C_{\mathrm{tr}} n_{\mathrm{c}} \ll 3
\end{gathered}
$$

Calculation of the second term of eq 7 is as follows. When $b=2,^{7,9,14}$

$$
\begin{aligned}
\int_{n_{\mathrm{c}}}^{\infty} n^{-2} & \exp \left(-C_{\mathrm{tr}} n\right) \mathrm{d} n \\
= & C_{\mathrm{tr}}{ }^{2} n_{\mathrm{c}}{ }^{3 / 2} \int_{z_{\mathrm{c}}}^{\infty} z^{-2} \exp (-z) \mathrm{d} z \\
= & C_{\mathrm{tr}} n_{\mathrm{c}}^{3 / 2}\left[1 / z_{\mathrm{c}}+\ln \left(z_{\mathrm{c}}\right)\right. \\
& \left.-\int_{z_{\mathrm{c}}}^{\infty} \ln (z) \exp (-z) \mathrm{d} z\right]
\end{aligned}
$$

To evaluate the third term of eq $\mathrm{A} 3$, an inequality A4 is considered.

$$
\begin{aligned}
\int_{z_{\mathrm{c}}}^{\infty} \ln \left(z_{\mathrm{c}}\right) \exp (-z) \mathrm{d} z & <\int_{z_{\mathrm{c}}}^{\infty} \ln (z) \exp (-z) \mathrm{d} z \\
& <\int_{z_{\mathrm{c}}}^{\infty} z \exp (-z) \mathrm{d} z(\mathrm{~A} 4)
\end{aligned}
$$

When $z_{\mathrm{c}} \ll 1$, this is calculated as

$$
\ln \left(z_{\mathrm{c}}\right)<\int_{z_{\mathrm{c}}}^{\infty} \ln (z) \exp (-z) \mathrm{d} z<z_{\mathrm{c}}+1
$$

In view of inequalities A5 and $1 / z_{\mathrm{c}} \gg|\ln (z)|>1+z_{\mathrm{c}}$, only the first terms of eq A3 is important, so that

$$
\int_{n_{\mathrm{c}}}^{\infty} n^{-2} \exp \left(-C_{\mathrm{tr}} n\right) \mathrm{d} n \simeq n_{\mathrm{c}}{ }^{1 / 2}
$$

When $b=1.5,2.9$, or $3.4,{ }^{4,6,15}$

$$
\begin{gathered}
\int_{z_{\mathrm{c}}}^{\infty} z^{-b} \exp (-z) \mathrm{d} z=\sum_{i=1}^{j} \frac{z_{\mathrm{c}}{ }^{i-b}}{(b-1) \cdots(b-i)} \\
+\frac{\int_{z_{\mathrm{c}}}^{\infty} z^{j-b} \exp (-z) \mathrm{d} z}{(b-1) \cdots(b-j)}
\end{gathered}
$$

where, at $0<j-b<1$,

$$
\begin{gathered}
\int_{z_{\mathrm{c}}}^{\infty} z^{j-b} \exp (-z) \mathrm{d} z<\int_{z_{\mathrm{c}}}^{1} \exp (-z) \mathrm{d} z \\
+\int_{1}^{\infty} z \exp (-z) \mathrm{d} z
\end{gathered}
$$

Accordingly, when $z_{\mathrm{c}} \ll 1$, eq $\mathrm{A} 7$ is reduced to be,

$$
\int_{z_{\mathrm{c}}}^{\infty} z^{-b} \exp (-z) \mathrm{d} z \simeq z_{\mathrm{c}}{ }^{1-b} /(b-1)
$$

\section{NOMENCLUTURE}

$\bar{k}_{\mathrm{t}} \quad=$ average termination rate constant

$k_{\mathrm{t}, \mathrm{ns}} \quad=$ rate constant of termination between polymer radicals with chain lengths $n$ and $s$

$k=$ rate constant between segment radicals

$a, b, \gamma \quad=$ constants for evaluating $\overline{k_{\mathrm{t}}}$

$\delta \quad=\gamma$ when $a=0$ and $\gamma / 2$ when $a=1 / 2$

$k_{\mathrm{p}} \quad=$ propagation rate constant

$k_{\mathrm{c}}, k_{1}, k_{-1}=$ constants for evaluating $k_{\mathrm{p}}$

$k_{\mathrm{d}} \quad=$ decomposition rate constant

$k_{\beta}, k_{\beta}^{\prime}=$ rate constant of $\beta$-scission

$f \quad=$ initiator efficiency

$A \quad=$ constant for evaluating $f$

$n_{\mathrm{c}} \quad=$ critical chain length

$n_{\mathrm{co}}=n_{\mathrm{c}}$ in an undiluted polymer solution 
$\left[\mathrm{N}_{n}\right]=$ concentration of polymer radical with $n$

[N] = total concentration of polymer radical

[C] = initiator concentration

$R_{\mathrm{i}} \quad=$ initiation rate $\left(=2 f k_{\mathrm{d}}[\mathrm{C}]\right)$

$R_{\mathrm{p}} \quad=$ polymerization rate $\left(=k_{\mathrm{p}}[\mathrm{M}][\mathrm{N}]\right)$

$C_{\mathrm{tr}} \quad=$ transfer constant

$\bar{p}_{\mathrm{w}} \quad=$ instantaneous weight-average degree of polymerization

$\bar{P}_{\mathrm{w}} \quad=$ integrated weight-average degree of polymerization

$x \quad=$ conversion

$c \quad=$ volume fraction of polymer

$\phi_{\mathrm{p}, \mathrm{gt}}=\mathrm{c}$ at which the system ${ }^{10,20}$ (polymerization solution) changes from a viscous liquid to a glassy state

$v_{\mathrm{f}} \quad=$ free volume

$\gamma^{*} \quad=$ overlap factor

$v^{*} \quad=$ critical free volume sufficient to permit a segment to jump into the place from which another segment has been displaced

$T_{\mathrm{gp}} \quad=$ glass-transition temperature of the polymer

$T_{\mathrm{gm}} \quad=$ glass-transition temperature of the monomer

$R \quad=$ reaction radius

$D \quad=$ diffusion constant of the polymer

$D_{\mathrm{s}} \quad=$ diffusion constant of a small radical

$u \quad=\left(C_{\mathrm{tr}} n\right)^{1 / 2}\left[u_{\mathrm{c}}=\left(C_{\mathrm{tr}} n_{\mathrm{c}}\right)^{1 / 2}\right]$

$z \quad=C_{\mathrm{tr}} n\left(z_{\mathrm{c}}=C_{\mathrm{tr}} n_{\mathrm{c}}\right)$

Acknowledgment. The author wishes to thank Nippon Oils and Fat Co., Ltd. for supplying the DIPDC.

\section{REFERENCES}

1. E. Trommsdroff, H. Kohle, and P. Lagally, Makromol. Chem., 1, 169 (1947).

2. A. W. Hui and A. E. Hamielec, J. Polym. Sci., 17, 905 (1968).

3. S. T. Balke and A. E. Hamielec, J. Appl. Polym. Sci., 17, 905 (1973).
4. K. Ito, J. Polym. Sci., Polym. Chem. Ed., 13, 401 (1975).

5. K. Ito, J. Polym. Sci., Polym. Chem. Ed., 13, 1297 (1975).

6. N. G. Kumar, J. Polym. Sci., Macromol. Rev., 15, 225 (1980).

7. P. G. de Gennes, "Scaling Concepts in Polymer Physics," Cornell University, Ithaca, New York, N. Y., 1979.

8. J. N. Cardenas and K. F. O'Driscoll, J. Polym. Sci., Polym. Chem. Ed., 14, 883 (1976).

9. K. Ito, Polym. J., 12, 499 (1980); ibid., 13, 727 (1981).

10. T. Ebihara, K. Horie, and I. Mita, Kobunshi Ronbunshu, 40, 499 (1983).

11. T. J. Tuling and M. Tirrel, Macromolecules, 14, 501 (1981); ibid., 15, 459 (1982).

12. S. K. Soh and D. C. Sundery, J. Polym. Sci., Polym. Chem. Ed., 20, 1299, 1315, 1331, 1345 (1982).

13. D. Punke, M. Stickler, and W. Wunderlich, Makromol. Chem., 184, 175 (1983).

14. H. M. Boots, J. Polym. Sci., Polym. Phys. Ed., 20, 1695 (1982).

15. P. G. de Gennes, J. Chem. Phys., 76, 3316, 3322 (1982).

16. F. Bueche, J. Appl. Pinys., 26, 738 (1955).

17. J. Klein, Macromolecules, 11, 852 (1978).

18. S. Onogi, T. Kobayashi, Y. Kojima, and T. Taniguchi, J. Appl. Poly. Sci., 7, 847 (1963).

19. K. Ito, J. Polym. Sci. A-1, 7, 2995 (1969); ibid., 8, 1313 (1970).

20. K. Horie, I. Mita, and H. Kambe, J. Polym. Sci. A-1, 6, 2663 (1968).

21. Kh. S. Bagdasa'yan, "Theory of Free-Radical Polymerization," Asakurashoten for Japanese Translation, Tokyo 1964: Israel Scientific Translations Jerusalem, 1968.

22. K. E. J. Barrett, J. Appi. Polym. Sci., 11, 1617 (1967).

23. F. Strain, W. E. Bissinger, W. R. Dial, H. Rundoff, B. J. De Witt, H. C. Stevens, and J. H. Hangston, J. Am. Chem. Soc., 72, 1254 (1950).

24. G. M. Burnett, Qart. Revs. (London), 4, 292 (1950).

25. H. K. Mahabadi and K. F. O'Driscoll, J. Macromol. Sci., Chem., A11, 967 (1977).

26. J. Van Hook and A. Tobolsky, J. Am. Chem. Soc., 80, 779 (1958).

27. B. W. Brooks, Proc. R. Soc. London, Ser. A, 357, 1983 (1977).

28. H. Kh. Mahabadi and G. Meyerhof, Proc. R. Soc. London, Ser. A, 15, 607 (1979).

29. K. Ito, J. Polym. Sci., Polym. Chem. Ed., 12, 1991 (1974); ibid., 15, 1759 (1977).

30. M. V. Smoluchowski, Z. Phys. Chem. (Leipzig), 92, 129 (1917).

31. G. V. Schulz, Z. Phys. Chem. (Frankflurt am Main), 8, 284 (1950).

32. P. J. Flory, "Principles of Polymer Chemistry," Cornell University Press, Ithaca, New York, N. Y., 
1953.

33. P. Hayden and H. Melville, J. Polym. Sci., 43, 201 (1960).

34. G. V. Schulz and G. Harborth, Makromol. Chem., 1, 106 (1947).

35. A. M. North, Quart. Rev., 20, 421 (1966).

36. E. W. Montroll, J. Chem. Phys., 14, 202 (1946).

37. M. Stickler, Makromol. Chem., 184, 2563 (1983).

38. K. Ito, Polym. Prepr., Jpn., 33, 1071 (1984).

39. W. A. Pryor and K. Smith, J. Am. Chem. Soc., 92, 5403 (1970).

40. R. M. Noyes, Progr. Reaction Kinetics, 1, 129 (1961).

41. O. Dobis, J. M. Pearson, and S. Szwarc, J. Am. Chem. Soc., 90, 283 (1968).
42. K. Chakravorty, J. M. Pearson, and S. Szwarc, $J$. Am. Chem. Soc., 90, 283 (1968).

43. K. Ito, J. Polym. Sci. A1, 10, 57 (1972).

44. W. A. Pryor, E. H. Morkvel, and H. T. Bickley, J. Org. Chem., 37, 1999 (1972).

45. W. Braun, L. Rajbenbach, and F. R. Eirich, J. Chem. Phys., 66, 1591 (1962).

46. T. Koenig and Deinzer, J. Am. Chem. Soc., 90, 7014 (1968).

47. T. Koenig, J. Am. Chem. Soc., 91, 2558 (1969).

48. J. Brandrup and H. Baunmann, "Polymer Handbook," John Wiley \& Sons, Inc., New York, N. Y., 1974.

49. J. Bartos and J. Tino, Polymer, 25, 274 (1984). 